
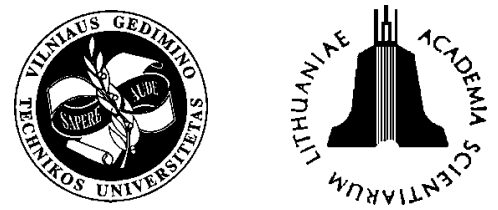

JOURNAL OF CIVIL ENGINEERING AND MANAGEMENT

http:/www.vtu.lt/english/editions

2004, Vol X, No 3, 183-190

\title{
BEHAVIOUR OF ALUMINIUM ALLOY STRUCTURES UNDER FIRE
}

\author{
Beatrice Faggiano ${ }^{1}$, Gianfranco De Matteis ${ }^{1}$, Raffaele Landolfo ${ }^{2}$, Federico M. Mazzolani ${ }^{1}$ \\ ${ }^{1}$ University of Napoli "Federico II", Faculty of Engineering, P.le Tecchio 80, 80125 Napoli, Italia. \\ E-mails: faggiano@unina.it; demattei@unina.it; fmm@unina.it 2University of Napoli “Federico II”, Faculty of \\ Architecture, Via Monteoliveto 3,80134 Napoli, Italia.E-mail: landolfo@unina.it
}

Received 18 Febr 2004; accepted 30 June 2004

\begin{abstract}
In the paper the attention is focused on the influence of high temperatures on the mechanical properties of the aluminium alloys selected by Eurocode 9 for structural uses. Therefore, based on the analysis of existing data taken from technical literature, the variation of the Young's modulus, the conventional yielding strength, the ultimate strength, the hardening factor and the material ultimate strain are represented as a function of the temperature. A mechanical model, based on the well-known Ramberg-Osgood formulation, which appropriately takes into account the peculiarities of such materials at high temperatures, is provided. In particular, the combined influence of the hardening factor and temperature on the material stress-strain relationship is considered and analysed. Then, the proposed model has been introduced in a finite element program, devoted to the global analysis of structures under fire. Finally, the results obtained for a simple portal frame structure, designed with different aluminium alloys, are presented, showing the valuable effect of the material modelling on the structural behaviour of aluminium structures under fire.
\end{abstract}

Keywords: aluminium alloys, mechanical properties under fire, effect of hardening, stress-strain relationships at high temperatures, structural analysis under fire.

\section{Introduction}

In recent years, the employment of aluminium alloys is increasing for constructing bridges, footbridges, aerials, offshore platforms, thanks to the material lightness, versatility and resistance to atmospheric agents. Therefore, there is the need for effective regulation of the design of aluminium alloy structures under fire. This, in fact, combines the increasing use of aluminium as a structural material with the more and more interest of the scientific community in the behaviour of civil and industrial constructions under conditions of exceptional temperature. Besides, it is worth noticing that the prediction of the mechanical response of aluminium alloy structures exposed to fire is particularly complicated for two principal reasons: on the one hand, the intrinsic difficulty of developing accurate structural analyses in postelastic field, taking correctly into account the mechanical features of the basic material, such as the strain-hardening and the limited deformation capacity; on the other hand, the inadequate knowledge of the material behaviour under high temperatures.

On the basis of the above considerations, also for aluminium alloy structures, it is necessary to develop and apply the advanced structural analysis methods [1]. Therefore the specific mechanical properties of the material as a function of the temperature must be considered. Thus, the whole stress-strain curve of the material, which already at the ambient temperature shows prominent characteristics of non-linearity, must be accurately defined as a function of the temperature, representing the variation law of the following characteristic parameters: the modulus of elasticity $(\mathrm{E})$, the elastic limit stress conventionally defined as $0,2 \%$ proof strength $\left(f_{0,2}\right)$, the ultimate strength $\left(f_{t}\right)$ and the ultimate deformation $\left(\varepsilon_{u}\right)$. In particular, the methods of structural analysis under fire conditions are to be held in due account: the influence of the shape of the whole material constitutive law and thus the kinematic strain hardening on the global behaviour of the structure. On the other hand, it must be considered that for allowing practical analysis in fire conditions of complex structures by the advanced methods, such accurate material models should be implemented in finite element programmes.

In this paper, the basic problems for the design and safety checks of the aluminium alloy structures under fire are faced. The attention is focused on the temperature influence on mechanical properties of the materials, with reference to the aluminium alloys selected by the Eurocode 9 for structural use [2]. Then, a mechanical model for the aluminium alloys, which appropriately represents the peculiarity of such materials subjected to high temperatures, is proposed. Such simplified constitutive 
law has been introduced in a finite element programme for the calculus of structures under fire [3]. Finally, the results of the structural analyses under fire obtained for a simple portal frame and carried out for different aluminium alloys are presented, clarifying the influence of the material modelling on the global response of the structure exposed to fire, evaluated in terms of time up to collapse and considering conventional fire scenarios [4].

\section{Fire analysis of aluminium alloy structures}

Generally, for the structural analysis under fire, from the point of view of the structural safety, it is necessary to identify adequate calculus methodologies, which allow the correct evaluation of the mechanical resistance of the structure. The more significant fire effects are: (1) deterioration of materials in strength and stiffness, which implies a reduction of the carrying capacity and worsening the deformation state; (2) thermal deformations, which may produce increase of second-order effects and/or internal stresses.

With regard to the fire modelling, as a simple alternative to real fire scenarios, reference is generally made to the so-called standard fires (for example, ISO 834 curve), which can be simply related to possible real fires by means of equivalence criteria. The design of structures under fire must essentially assure that in case of fire, according to the chosen thermal programme, the static safety is guaranteed for a pre-fixed period of time, to be associated to the class of fire resistance imposed by the standard rules. It is clear that the analysis under fire of complex structures must account for all those factors that are not considered by the simplified methods, for instance, geometric and mechanical non-linearities, creep phenomena, residual stresses, thermal deformations and the real evolution of the mechanical behaviour of the material under the temperature. Evidently, the application of such methodologies cannot avoid using the finite element programme.

At the European level, the main references for codifications are given by the Eurocodes: EC 1-Part 2-2, for the applied loads in fire conditions [5]; EC 2- Part 1-2, for reinforced concrete structures under fire [6]; EC 3Part 1-2, for steel structures under fire [7]; EC 9- Part $1-2$, for aluminium alloys structures under fire [2].

Such provisions can be considered exhaustive and reliable in case of the most common materials, such as steel and reinforced concrete, while they result more approximated in the case of the aluminium alloys structures, mainly due to the difficulties of accurate and reliable material modelling. Therefore, it appears convenient to go more deeply into the problem, checking the opportunity of applying for code purposes a better schematisation of the mechanical behaviour of the material, so as to allow the maximum exploitation of the resistance resource of the material, which, generally, results are highly vulnerable under fire.

\section{Mechanical features of aluminium alloys at high temperatures}

Common aluminium alloys melt at about $600{ }^{\circ} \mathrm{C}$ and loose the $50 \%$ of their original strength at about $200{ }^{\circ} \mathrm{C}$ $[8,9]$. The principal behaviour parameters, such as the stress at the conventional elastic limit $\left(f_{0,2, \mathrm{~T}}\right)$ and the elastic modulus $\left(E_{\mathrm{T}}\right)$, as a function of the temperature, are depicted in Fig 1, according to EC9 [2]. In particular, in Fig 1a the conventional strength $f_{0,2}$ is given through the reduction coefficient $k_{0,2, \mathrm{~T}}$, which provides for each alloy the ratio between the elastic strength at a given temperature $\left(f_{0,2, \mathrm{~T}}\right)$ and the elastic strength at ambient temperature $\left(f_{0,2}, 2\right.$.

(a)

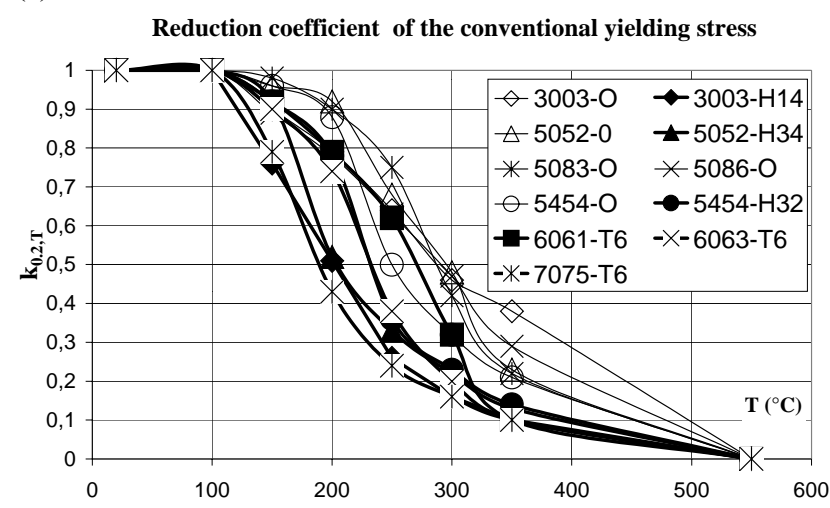

(b)

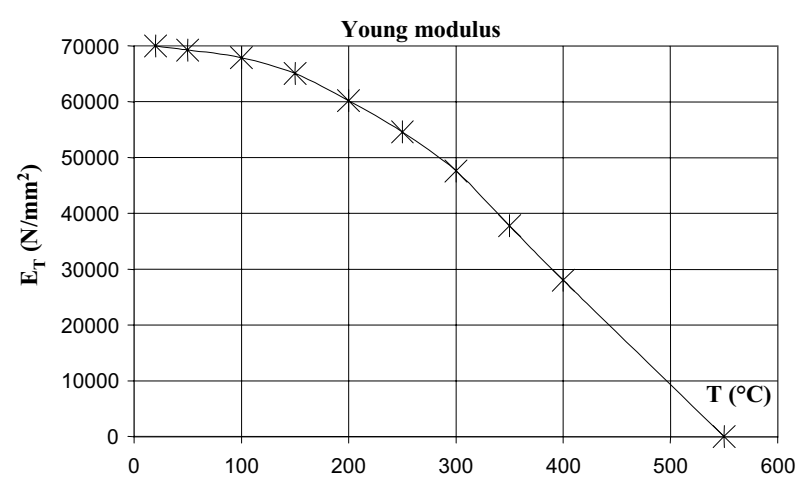

Fig 1. Mechanical properties of the examined aluminium alloys as a function of temperature: (a) $k_{0.2, \mathrm{~T}}$, (b) $E_{\mathrm{T}}$

It can be noticed that the alloys in the work hardening state $(\mathrm{H})$ and the ones being in the hardening state by means of heat treatment $(\mathrm{T})$ exhibit a relevant loss of strength with temperature, which is of about $70-80 \%$ at $250^{\circ} \mathrm{C}$. Besides, the alloys in the annealed state $(\mathrm{O})$ show a less significant decay of strength, which is of about $30-50 \%$ at $250{ }^{\circ} \mathrm{C}$. Also, it can be observed that the elastic modulus $E$ decreases as far as the temperature increases, independently of the alloy and its treatment (Fig 1b).

Fig 2 shows the variation laws of the conventional yielding stress $f_{0,2, \mathrm{~T}}$, the ultimate strength $f_{t, \mathrm{~T}}$, the hard- 
(a)

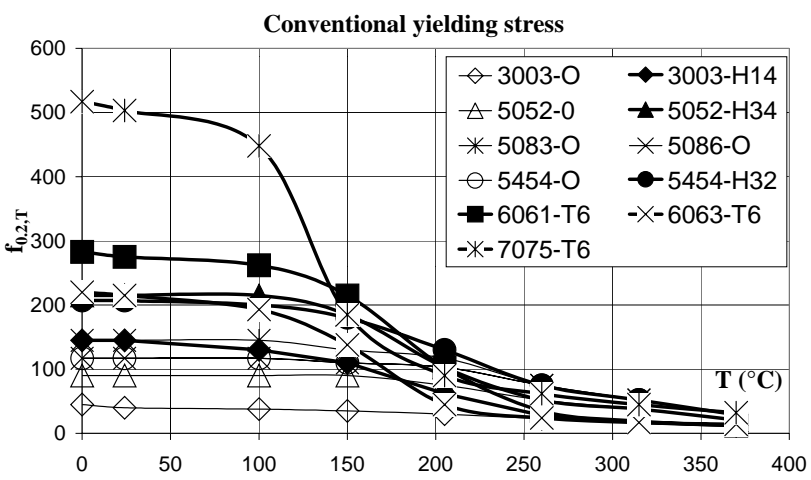

(b)

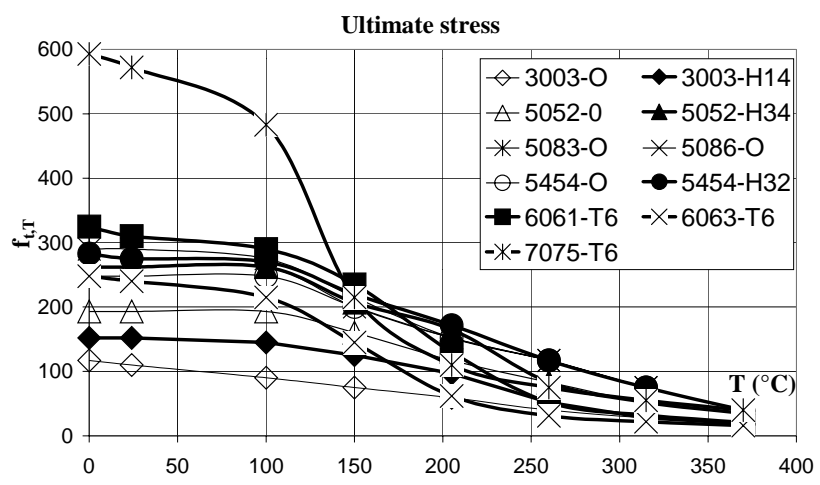

(c)

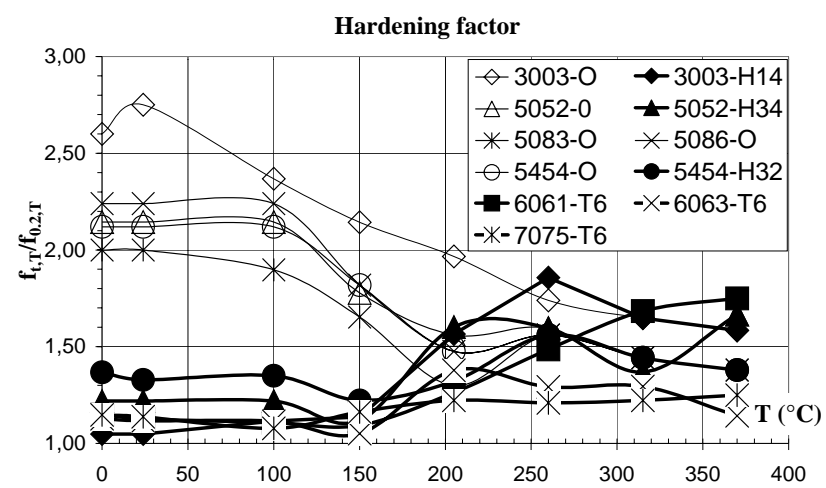

(d)

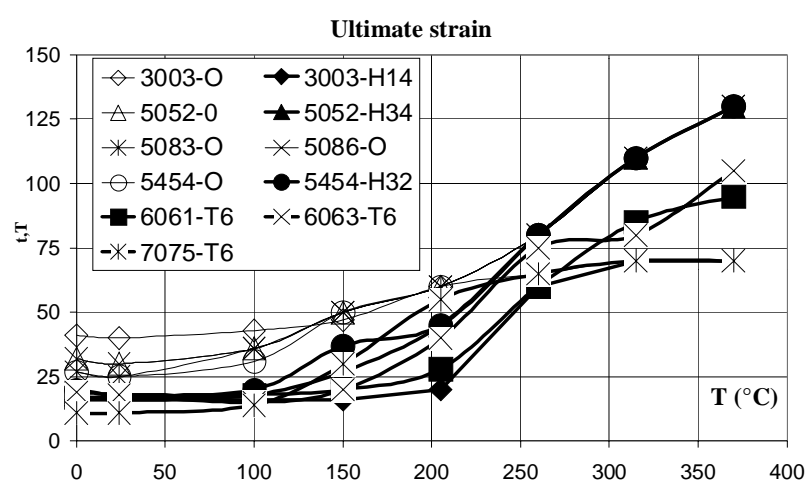

Fig 2. Effect of temperature on the mechanical properties of the examined aluminium alloys: (a) $\mathrm{f}_{0.2, \mathrm{~T}}\left(\mathrm{~N} / \mathrm{mm}^{2}\right)$, (b) $\mathrm{f}_{\mathrm{t}, \mathrm{T}}\left(\mathrm{N} / \mathrm{mm}^{2}\right)$, (c) $\mathrm{f}_{\mathrm{t}, \mathrm{T}} / \mathrm{f}_{0.2, \mathrm{~T}}$, (d) $\varepsilon_{\mathrm{u}, \mathrm{T}}(\%)$ ening ratio $f_{t, \mathrm{~T}} / f_{0,2, \mathrm{~T}}$ and the elongation at rupture $\varepsilon_{u \text {, }}$ as a function of the temperature, based on data available in technical literature. They are related to experimental tensile tests carried out in oven with specific procedures, corresponding to exposures of 10000 hours at high temperatures [10].

Such diagrams show that heat treated and work hardened alloys (types $\mathrm{T}$ and $\mathrm{H}$ ) are characterised by ultimate strength remarkably larger than the alloys in the annealed state (type $\mathrm{O}$ ), only up to temperatures of about $100-150{ }^{\circ} \mathrm{C}$. From Fig $2 \mathrm{c}$ it can be also noted that while at ambient temperature annealed state alloys (type $\mathrm{O}$ ) present a strain hardening ratio $\left(f_{t} / f_{0,2}\right)$ about twice larger with respect to the heat treated and work hardened alloys (types $\mathrm{T}$ and $\mathrm{H}$ ), such difference strongly reduces as far as the temperature increases, starting from temperatures of about $100-150{ }^{\circ} \mathrm{C}$. In particular, for notreated alloys the strain hardening decreases with the increment of the temperature, while in case of the treated alloys it increases, approaching in both cases a value next to 1,5 . Then, it can be generally observed that treatments, such as the tempering and the plastic working processes, improve the material strength, but in the meantime they reduce both the effect of the strain hardening and the extent of the ultimate elongation $\left(\varepsilon_{u}\right)$, which experiences a revival with the increase of the temperature.

Further data available in literature [11] show that the resistance of the aluminium alloys, given in terms of both conventional yielding stress and ultimate strength, decreases as far as the exposure time to an assigned temperature increases. On the contrary, the ultimate elongation, and then the material ductility, increases with the prolonged permanence at high temperatures.

Finally, other thermal properties, such as the thermal expansion, the specific heat and the thermal conductivity, undergo an increment with the temperature increase. Besides, the variation law of such properties, as indicated in EC9, results almost independent of the alloy type.

\section{Stress-strain relations for aluminium alloys at high temperatures}

The modelling of the constitutive law of aluminium alloys evidences remarkable difficulty already at ambient temperature, due to a high variation in the mechanical behaviour among the different alloys and the adopted fabrication processes. Besides, experimentally obtained $\sigma-\varepsilon$ curves are not well fitted by simplified diagrams, like the elastic-perfectly plastic one, due to the remarkably continuous hardening exhibited in the plastic range.

For the structural analysis under high temperatures, Eurocode 9 makes implicitly reference to the adoption of a simplified relationship of the elastic-perfectly plastic type, exclusively supplying the variation of the elastic modulus and of the conventional yielding stress with the temperature (Fig 3a). 
In order to interpret more correctly the evolution of the mechanical characteristics of the material with the temperature, it would be possible to apply the RambergOsgood model, which is already commonly used for modelling aluminium alloy at ambient temperature for non-linear analyses [8]. The general expression of the Ramberg-Osgood law at ambient temperature for analyses in the large deformation field can be assumed as:

$$
\begin{gathered}
\varepsilon=\frac{\sigma}{E}+0,002\left(\frac{\sigma}{f_{0,2}}\right)^{n}, \\
\text { where } n=\frac{\log \frac{0,002}{\varepsilon_{u}}}{\log \frac{f_{0,2}}{f_{t}}} .
\end{gathered}
$$

The $n$ exponent measures the strain hardening of the alloy, ruling the shape of the curve in the post-elastic field. In particular, it can be observed that for values of the $n$ factor approaching 0 the Ramberg-Osgood law gives an indefinitely elastic behaviour, while for large values of $n$ factor an elastic-perfectly plastic behaviour is obtained (Fig 3b).

(a)

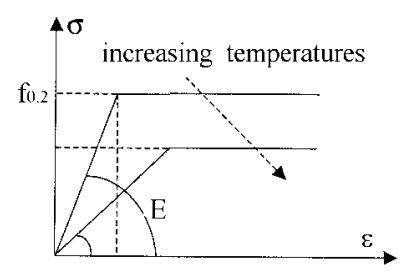

(b)

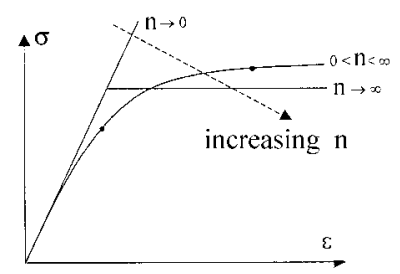

Fig 3. Typical constitutive laws for the aluminium alloys: (a) elastic-perfectly plastic law, (b) Ramberg-Osgood relationship

The extension of the Ramberg-Osgood relationship to high temperature is based on the introduction of the variation law with the temperature of all the relevant mechanical parameters, such as $f_{0,2, \mathrm{~T}}, \varepsilon_{\mathrm{u}, \mathrm{T}}$ and $f_{t, \mathrm{~T}}$. Such variation laws could be assumed as the ones already drawn in Fig 2.

On the basis of the elaboration of the variation laws for the single parameter (Fig 4), for each considered alloy, the values of the strain hardening factor $n$ obtained at different levels of temperature, included the ambient temperature, are depicted. In particular, in order to evidence the influence of the mechanical properties on the strain hardening factor $n$, the value obtained considering the actual variation of the single mechanical parameters with temperature (n-analytical), is compared to the $n$ values obtained taking the ultimate elongation as a constant and equal to the value at ambient temperature $\left(n-\varepsilon_{u}=\right.$ cost $)$ and the constant value of $n$ at ambient temperature.
First of all, it can be observed that for all the alloys the $n$ value for high temperatures is remarkably different with respect to that one obtained at ambient temperature. Furthermore the $n(\mathrm{~T})$ relationship does not present a single trend for the different examined materials. In particular, for not treated materials (type O) it can be noted that at increasing temperatures the strain hardening factor exhibits an increment higher than $50 \%$ with respect to the room temperature value. On the contrary, for treated materials ( $\mathrm{H}$ and $\mathrm{T}$ types) the $n$ value is higher than the corresponding value at ambient temperature, only up to a temperature of about $200{ }^{\circ} \mathrm{C}$, beyond which there's a reversal trend, with values of the $n$ factor lower than the ones at ambient temperature.
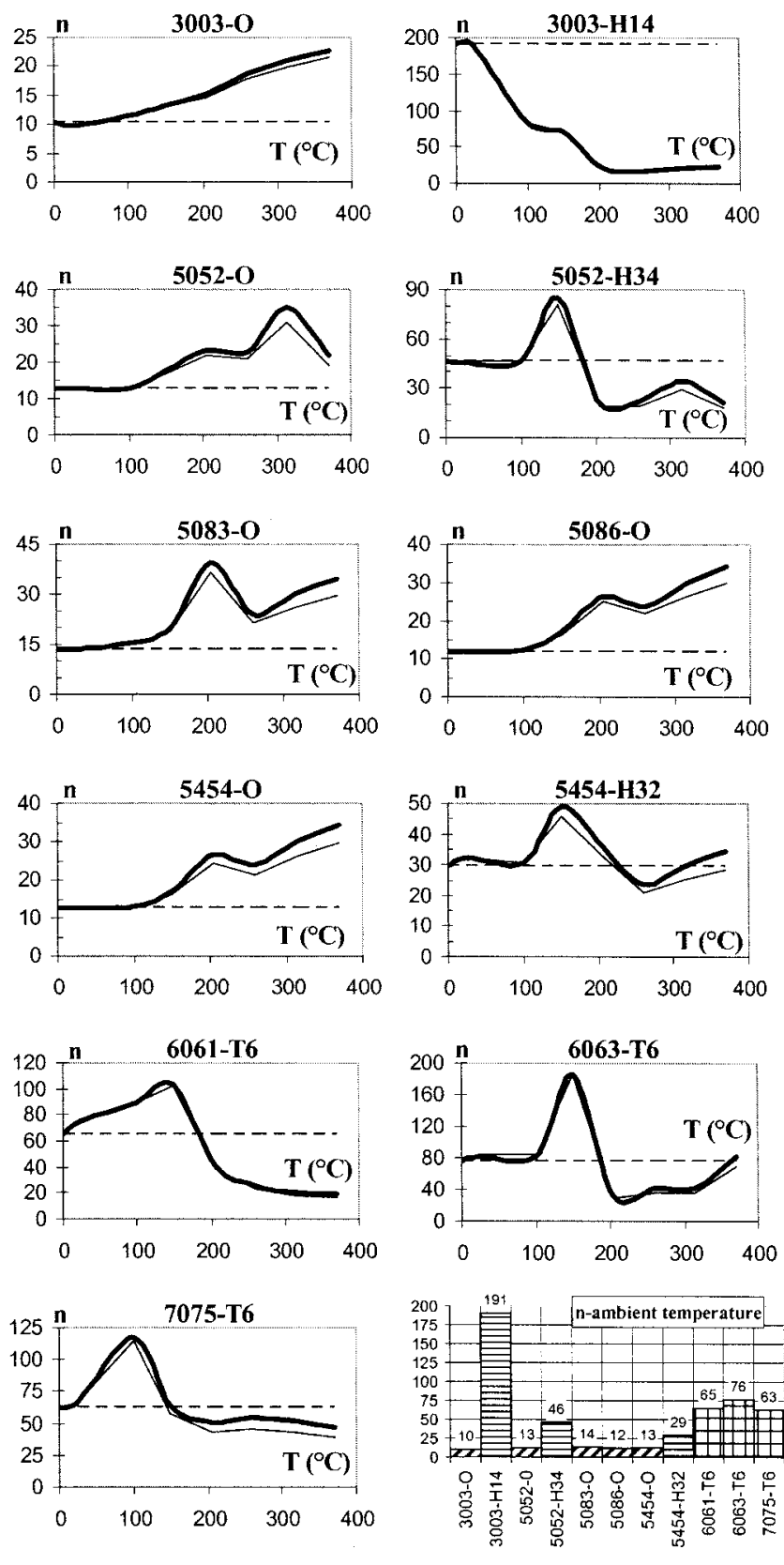

n-analytical $\longrightarrow \mathrm{n}$-eu=cost $-\cdots-$ n-constant

Fig 4. The strain hardening factor $n$ as a function of temperature 
Moreover, it can be observed that the variation of the elongation at collapse $\varepsilon_{\mathrm{u}}$ with the temperature does not produce a significant influence on the strain hardening factor $n$. As a consequence, in order to simplify the mathematical expression of the strain hardening factor, the ultimate elongation of the material could be actually taken constant and equal to the one at ambient temperature.

In order to emphasise the influence of the strain hardening factor on the constitutive law of aluminium alloys at high temperatures (Fig 5), for every examined alloy, the $\sigma-\varepsilon$ curves are represented at different temperatures $\left(24^{\circ} \mathrm{C}, 150^{\circ} \mathrm{C}, 315^{\circ} \mathrm{C}\right)$, considering different hypotheses of hardening factor evaluation, namely: (1) actual hardening factor $n$ with temperature (n-analytical); (2) constant value equal to the one at ambient temperature (n-constant); (3) constant value equal to 200 (n-200), the latter being representative of an elastic-perfectly plastic mechanical behaviour.
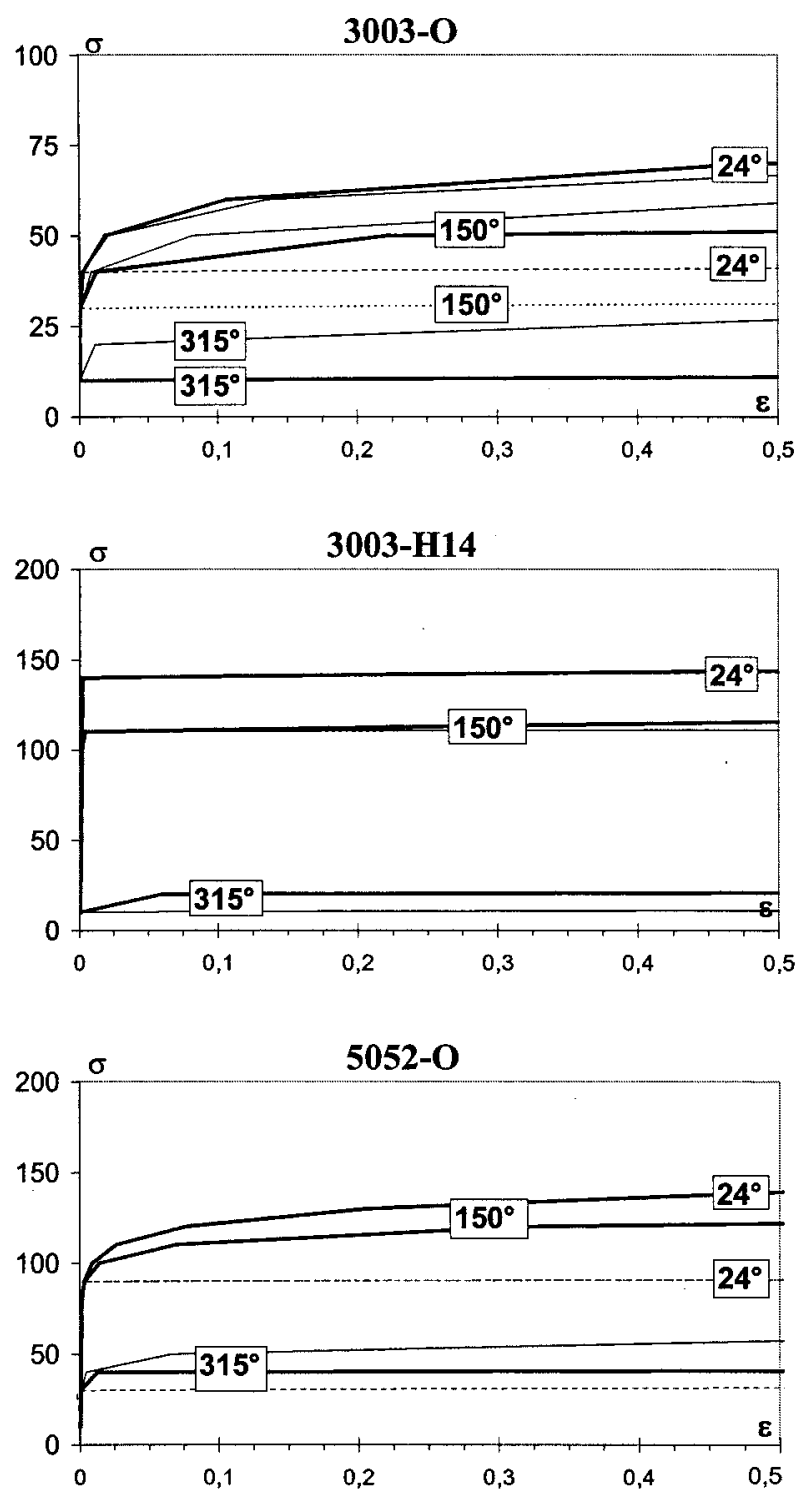
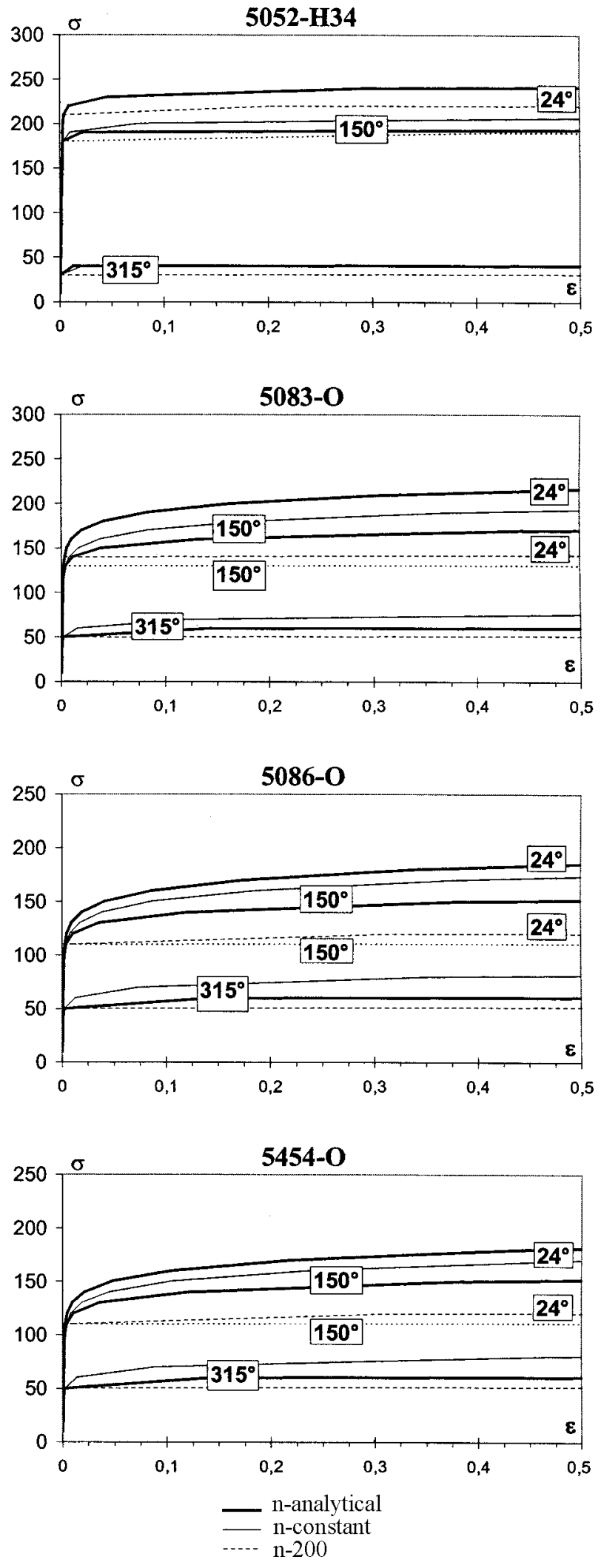

Fig 5. The $\sigma\left(\mathrm{N} / \mathrm{mm}^{2}\right)-\varepsilon$ laws for the aluminium alloys at different temperatures (continued) 

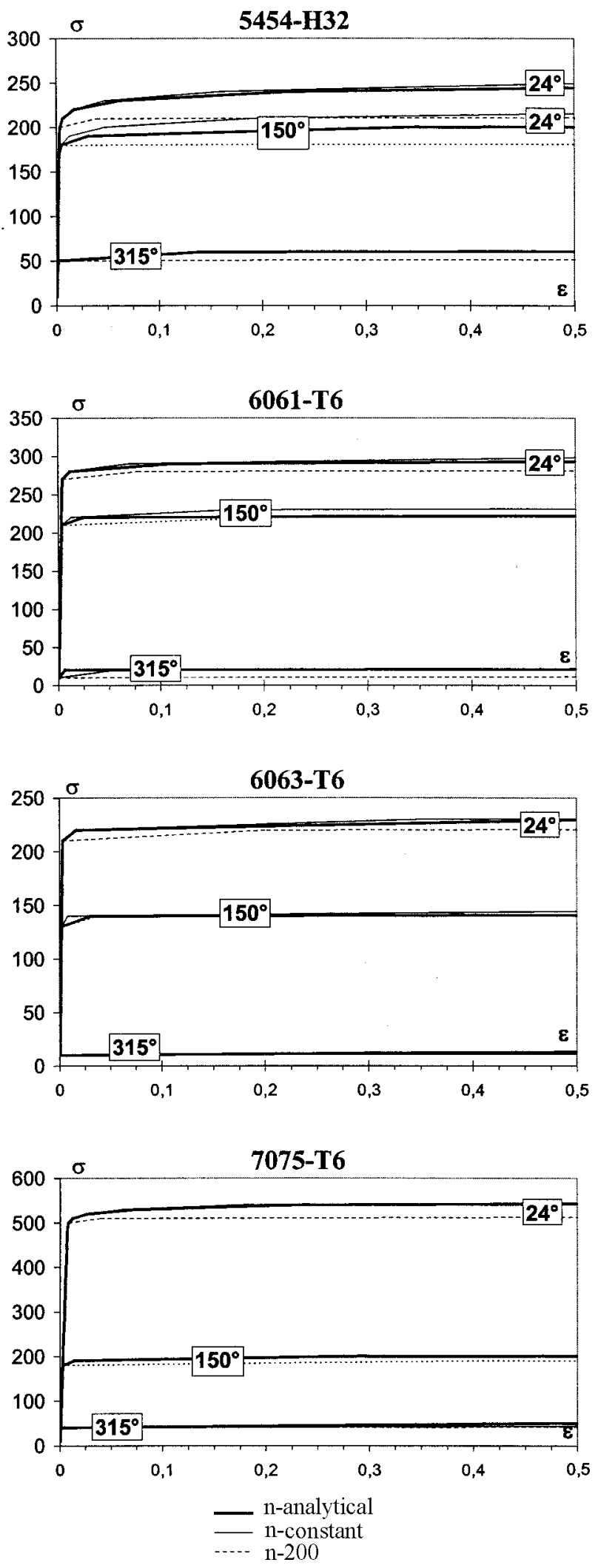

Fig 5. The $\sigma\left(\mathrm{N} / \mathrm{mm}^{2}\right)-\varepsilon$ laws for the aluminium alloys at different temperatures (continued)
The obtained diagrams show that the mechanical behaviour of the aluminium alloys at high temperatures is generally significantly conditioned by the strain hardening factor $n$. Such effect appears more evident in case of the alloys in the annealed state $(\mathrm{O})$, for which at high temperatures the $n$ factor (Fig 5) remarkably increases, producing $\sigma-\varepsilon$ curves characterised by strain hardening much lower than the one at ambient temperatures. It is also evident that the assumption of $n$ constant and equal to the value at ambient temperature is unconservative for such type of alloys. On the contrary, for treated alloys the influence of the $n$ factor is generally less important, particularly for heat-treated alloys $(\mathrm{T})$, where the strain hardening of the material is very low at ambient temperature as well. Finally, it can be observed that for all the examined alloys, for temperatures higher than $200{ }^{\circ} \mathrm{C}$, the constitutive law can be adequately schematised by using the elastic-perfectly plastic model.

\section{Influence of material modelling on global analysis}

Assessing the influence of modelling of the material on the fire resistance of aluminium structures, hereafter the structural analysis under fire condition of a simple plane portal frame made of different aluminium alloys is presented. The geometric characteristics, the load conditions, the fire event model as well as the exposure condition to fire of the structural members are presented in Fig 6, together with the types of considered alloys and the result of the member sizing.

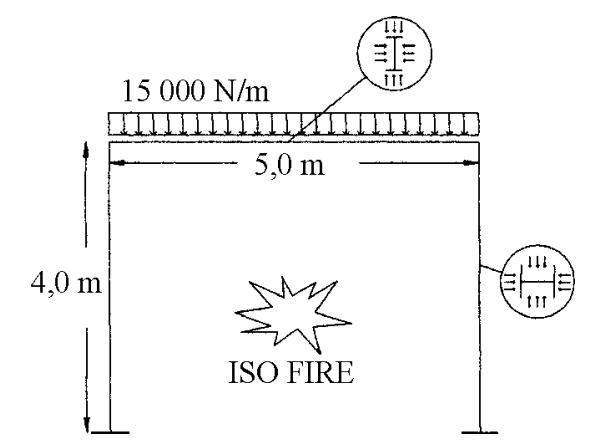

\begin{tabular}{|l|l|l|l|}
\hline ALLOY & $\begin{array}{l}f_{0.2, d} \\
\left(\mathrm{~N} / \mathrm{mm}^{2}\right)\end{array}$ & $\begin{array}{l}\text { Column } \\
\text { HEB }\end{array}$ & $\begin{array}{l}\text { Beam } \\
\text { IPE }\end{array}$ \\
\hline $3003-\mathrm{O}$ & 45 & 160 & 450 \\
$3003-\mathrm{H} 14$ & 145 & 160 & 300 \\
$5052-\mathrm{O}$ & 90 & 160 & 330 \\
$5052-\mathrm{H} 34$ & 215 & 160 & 240 \\
$5454-\mathrm{O}$ & 117 & 160 & 300 \\
$5454-\mathrm{H} 32$ & 207 & 160 & 240 \\
$5083-\mathrm{O}$ & 145 & 160 & 300 \\
$5086-\mathrm{O}$ & 117 & 160 & 300 \\
$6061-\mathrm{T} 6$ & 283 & 160 & 240 \\
$6063-\mathrm{T} 6$ & 220 & 160 & 240 \\
$7075-\mathrm{T} 6$ & 517 & 160 & 240 \\
\hline
\end{tabular}

Fig 6. Study cases 
For the analysis of the structure under fire, the finite element program SAFIR98a [3], developed by J. M. Franssen of the University of Liége, has been used. Such a software has been upgraded (2002) by implementing also the material models for aluminium alloys provided by Eurocode 9. In particular, in order to assess the influence due to the strain hardening on the behaviour of the whole structural complex, different material models based on the Ramberg-Osgood law have been considered, assuming (1) the actual strain hardening factor $n$ (n-analytical), (2) a constant value equal to the one at ambient temperature (n-constant) and (3) $n$ equal to 200 (n-200), this latter corresponding to the elastic-perfectly plastic model as implicitly assumed in EC9-Part-1-2. The used software allows to consider element models characterised by spread plasticity.

In Fig 7 the results of the analysis, given in terms of fire resistance of the structure $(\mathrm{R})$ expressed in minutes, are specified. The structural resistance $\mathrm{R}$ has been also normalised, considering as reference value for each alloy the one corresponding to the material model based on the actual strain hardening value (n-analytical). In the above analysis, the considered collapse condition corresponds to the loss of stability of the structure, which occurs when, due to the deterioration of the mechanical features of the material induced by the temperature, it is not able to balance the applied external loads.

\begin{tabular}{|l|l|l|l|}
\hline \multirow{2}{*}{ ALLOY } & \multicolumn{3}{|c|}{ Fire resistance (min) } \\
\cline { 2 - 4 } & n-analytical & n-constant & n-200 \\
\hline $3003-\mathrm{O}$ & 6 & 6 & 4 \\
$3003-\mathrm{H} 14$ & 6 & 5,40 & 5 \\
$5052-\mathrm{O}$ & 7,20 & 8 & 5,20 \\
$5052-\mathrm{H} 34$ & 6 & 5,40 & 5,20 \\
$5083-\mathrm{O}$ & 7,40 & 8 & 6,20 \\
$5086-\mathrm{O}$ & 7,40 & 8 & 6,40 \\
$5454-\mathrm{O}$ & 7,40 & 8 & 6,40 \\
$5454-\mathrm{H} 32$ & 7 & 6,40 & 6 \\
$6061-\mathrm{T} 6$ & 5,20 & 5,20 & 5,20 \\
$6063-\mathrm{T} 6$ & 7 & 7 & 6,20 \\
$7075-\mathrm{T} 6$ & 6,40 & 6,20 & 5,20 \\
\hline
\end{tabular}

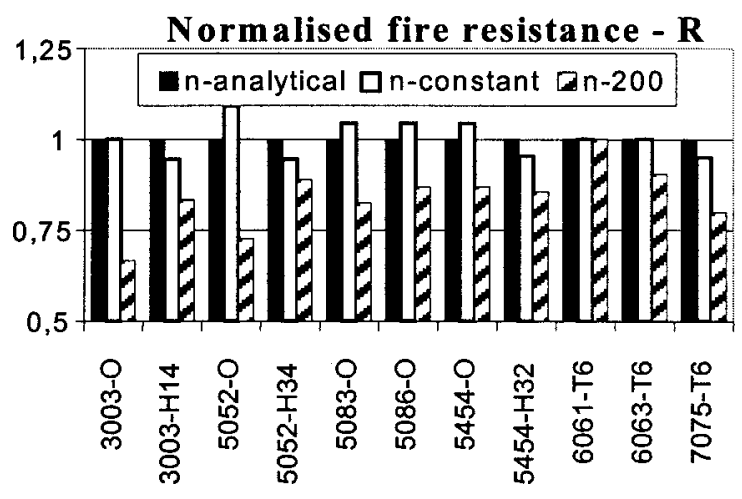

Fig 7. Fire resistance for the study cases
The examination of the obtained results evidences that the effect of the strain hardening factor on the global behaviour of the structure is similar to that already obtained at the material model level. Generally, the fire resistance of the portal frame is higher in case of material model with constant value at ambient temperature of the factor $n$, while it is lower when the elastic-perfectly plastic material model is used. In particular, it can be observed that in most unfavourable conditions (3003-O and 5052-O alloys), when considering the elastic-perfectly plastic material model, a fire resistance reduction of the structure of about $30 \%$ is gained. Besides it can be pointed out that not treated alloys $(\mathrm{O})$ give rise to the best behaviour under fire due to the beneficial effect of material strain hardening.

However, it is worth noticing that the presented results are somewhat restricted, being referred to a simple portal frame structures.

Moreover, it has to be evidenced the limited collapse time, which on average is equal to about $7 \mathrm{~min}$ utes. Anyway, this limited fire resistance refers to a specific structural scheme, considering a standard fire model and the worse exposure condition of the frame members (unprotected, 4 sides exposure and inconvenient crosssection shape). Consequently, considerable margins of improvement of the performances to fire of the structure exist.

Nonetheless, it must be evidenced that the main aim of the study is a more comparative evaluation of the strain hardening at high temperatures for different aluminium alloys for structural uses and its impact on the structural fire resistance than the optimization of the behaviour of structures under fire conditions.

\section{Conclusive remarks}

In order to set up advanced fire design methods for aluminium alloy structures, in this paper the influence of temperature on the mechanical properties of the material has been analysed, taking into considerations all the alloys selected by Eurocode 9 for structural uses. Particular attention has been focused on material strain hardening, which characterises the mechanical behaviour of the material in plastic range. In fact, as a first result of the study, it has been pointed out that simplified mechanical models, such as the elastic-perfectly plastic one, generally are not able to correctly characterise the material behaviour at high temperatures, since they disregard the beneficial effect due to continuous material hardening, which is somewhat effective in balancing strength decay due to high temperatures. Therefore, in order to take specifically into account the effect of the strain hardening, a more comprehensive mechanical model for aluminium alloys has been proposed, based on the well known Ramberg-Osgood law, which is able to represent in an appropriate manner all the peculiarities of such materials exposed to high temperatures. Then, such model has 
been introduced in a finite element program for global analysis of structures subjected to fire. The structural analysis in fire conditions of a study case related to a simple portal frame has pointed out the remarkable effect of material modelling for aluminium alloys, since the adoption of elastic-perfectly plastic model results are very conservative and not convenient for a material which exhibits a rapid strength decay with high temperature.

\section{References}

1. Wald, F.; Bosiljkov, V.; De Matteis, G.; Haller, P.; Vila Real, P. Structural integrity of buildings under exceptional fire. In: 1st Cost C12 Seminar, Lisbon 18-19 April, 2002.

2. prEN 1999-1-2. Eurocode 9: Design of aluminium structures - Part 1-2: General rules-Structural fire design, European Communities for Standardisation, Brussels, 2003.

3. Franssen, J. M. SAFIR98a - User's Manual. University of Liege, 1998.

4. Faggiano, B.; De Matteis, G.; Landolfo, R.; Mazzolani, F. M. On the behaviour of alluminium alloy structures exposed to fire. In: Proceedings of the XIX National Con- gress C.T.A.: III week of steel Constructions, 28-30 Sept, Genova, 2003, p. 393-406.

5. EN 1991-1-2. Eurocode 1: Basis of design and actions on structures - Part 2-2: Actions on structures - Actions on structures exposed to fire, European Communities for Standardisation, Brussels, 2002.

6. prEN 1992-1-2. Eurocode 2: Design of reinforced concrete structures - Part 1-2: General rules-Structural fire design, European Communities for Standardisation, Brussels, 2002.

7. prEN 1993-1-2. Eurocode 3: Design of steel structures Part 1-2: General rules-Structural fire design, European Communities for Standardisation, Brussels, 2003.

8. Mazzolani, F. M. Aluminium alloy structures. 2nd edn., E\&FN Spon, London, 1994, UK.

9. Lundberg, S. Design for fire resistance. In: Training in Aluminium Application Technology (TALAT) EUCOMETT Program, F. Ostermann Ed., Aluminium Training Partnership, Brussels: Section 2500, 1995.

10. ASM Specialty Handbook. Aluminium and aluminium alloys. Edited by J. R. Davis Davis \&Associates, 1993.

11. Conserva, M.; Donzelli, G.; Trippodo, R. Aluminium and its application. EDIMET, 1992. 